\title{
Inventar o fora como um dentro e fazer da clau- sura uma educação
}

\section{Resumo}

Luiz Carlos Quirino da Silva

Máximo Daniel Lamela Adó

Universidade Federal do Rio Grande do Sul (Brasil)

Este texto problematiza as possibilidades inventivas envolvidas numa aula (entendida aqui como inseparável da produção de pensamento) sob as condições restritivas impostas pela pandemia causada pelo novo coronavírus. Parte do pressuposto de que para que o pensamento aconteça, é fundamental seu contato com as forças do que Deleuze (2005), Foucault (2006) e Blanchot (201 1) chamaram de Fora. Por isso, o texto propõe um procedimento poético assentado numa espécie de máquina de leitura e de tradução como possibilidade de contato com tais forças. $E$, como base e possibilidade para essa invenção em educação, elege um tipo de leitura que falseia os materiais com que se depara e que, num certo sentido, desrespeita-os. Defende a ideia de que tal movimento, em condições de enclausuramento, só se torna possível porque o dentro é constituído pela dobra do Fora sobre si. Em tais condições, a invenção de uma aula teria, então, de virar pelo avesso essa dobra e produzir algo como uma linguagem para aquilo que ainda não sabemos.

Palavras-chave: Pandemia. Educação. Fora. Máquina de leitura.

\section{Inventing the outside as an inside and making the enclosure an education}

\begin{abstract}
This text problematizes the inventive possibilities involved in a class (understood here as inseparable from the thought production) under the restrictive conditions imposed by the pandemic caused by the new coronavirus. It starts from the assumption that for thought to happen, its contact with the forces of what Deleuze (2005), Foucault (2006) and Blanchot (2011) have called Outside is fundamental. Therefore, the text proposes a poetic procedure supported on a kind of reading and translation machine as a possibility of contact with such forces. And, as a basis and possibility for this invention in education, it chooses a type of reading that distorts the materials it encounters and, in a certain sense, disrespects them. It defends the idea that such movement, in confinement conditions, only becomes possible because the inside is constituted by the fold of the Outside upon itself. Under such conditions the invention of a class would, then, have to turn this fold inside out and produce something like a language for what we don't yet know.

Keywords: Pandemic. Education. Outside. Reading machine.
\end{abstract}




\section{Inventar el afuera como un adentro y hacer del encierro una educación}

\section{Resumen}

Este texto problematiza las posibilidades de invención de una clase (entendida aquí como inseparable de la producción de pensamiento) en las condiciones restrictivas impuestas por la pandemia provocada por el nuevo coronavirus. Parte del supuesto de que para que el pensamiento se produzca, es fundamental su contacto con las fuerzas de lo que Deleuze (2005), Foucault (2006) y Blanchot (2011) llamaron el Afuera. Por ello, el texto propone un procedimiento poético basado en una especie de máquina de lectura y traducción como posibilidad de contacto con dichas fuerzas. Y, como base y posibilidad de esta invención en la educación, elige un tipo de lectura que distorsiona los materiales con los que se encuentra y que, en cierto sentido, les falta el respeto. Defiende la idea de que tal movimiento, en condiciones de encierro, sólo es posible porque el adentro está constituido por el pliegue del Afuera sobre sí mismo. En tales condiciones, la invención de una clase tendría, entonces, que dar la vuelta a este pliegue y producir algo así como un lenguaje para lo que aún no conocemos.

Palabras claves: Pandemia. Educación. Afuera. Máquina de lectura.

\section{Introdução ao confinamento}

A pandemia provocada pelo novo coronavírus (Sars-CoV-2), que causa a doença respiratória que ficou conhecida como covid-19, perturbou significativamente a realidade como a conhecíamos até então. Quanto a esse ponto, temos a impressão de que não há muito do que se possa discordar. Além disso, há o fato de que ainda não havia vacinas quando a doença surgiu - e de que apenas agora (depois do desenvolvimento de um imunizante) tenha começado uma lentíssima vacinação em massa da população - nos lançou num interminável distanciamento social. Isso implicou na suspensão de todas as atividades não essenciais ou que representassem risco de proliferação da doença, incluindo todas as atividades de ensino. De um momento para outro, professores e alunos (e suas famílias) foram obrigados a se adaptar a um contexto educativo totalmente inédito, marcado pelas incertezas, pela sobrecarga de trabalho e pelo esgotamento de quase todos os envolvidos. Não sabemos por quanto tempo ainda teremos que enfrentar os perigos do vírus e a nova configuração educacional (que talvez tenha chegado para ficar), o que torna premente que repensemos nossas práticas enquanto professores e alunos e, por que não, enquanto comunidade. Teremos de reaprender a habitar neste mundo 
estranho, como estrangeiros dentro de nossa própria pátria ou numa pátria que se estrangeiriza - familiar, mas ao mesmo tempo, outra.

\section{O Fora e a despossessão}

Gilles Deleuze, Michel Foucault e Maurice Blanchot desenvolveram, através de leituras e de influências recíprocas, a ideia de que a possibilidade da criação de algo- seja de uma obra artística, literária ou mesmo do pensamento - passa por uma operação de "variação intensiva" (LAPOUJADE, 2015) que conduz seus elementos até um limite, muito próximo da destruição e que, em alguns casos, pode consumar-se de fato. Um limite que, apesar de ter sido chamado de Fora, não se confundiria com a simples exterioridade. No caso da ficção, por exemplo, Foucault dirá que é o lugar onde nascem as suas imagens. No entanto, estas não partem nem do mundo nem dos homens, mas de algo que se passa entre ambos, de uma força que circula entre eles, num entrelugar. Ponto de difícil identificação, por onde tal força se movimenta "[...] na impossivel verossimilhança do que está entre eles" (FOUCAULT, 2006, p. 225). A possibilidade da literatura, da palavra em sua forma literária, residiria numa insolúvel contradição, como aponta Blanchot, porquanto a afirmação de sua autonomia, através da construção de sua própria realidade, consistiria na negação da realidade em si. Apesar da literatura estar sempre ancorada nesse real que, porém, apresenta-se agora como negativo (LEVY, 2011 ). A linguagem, então, apontaria numa direção impossível, de denúncia de seu próprio desaparecimento constitutivo. Estaria destinada ao fracasso, mas que, em alguns momentos, consegue obter algum êxito - como quando assume a forma poética: "Esse ponto é aquele em que a realização da linguagem coincide com seu desaparecimento [...] a aparência do que despareceu [...]" (BLANCHOT, 2011 , p. 38). Tal espaço é o Fora: o lugar dos movimentos violentos, impossíveis e intermináveis das forças de gênese que constituem o pensamento como sua dobra, coextensivas de um dentro, ou seja, de nosso próprio dentro (DELEUZE, 2005). Lugar de circulação das forças diferenciais, ao mesmo tempo o Fora da força sua distância e diferença potencial (PELBART, 1989). Pensar, só seria possível nesse espaço onde o mais longínquo é também o seu interior. Assim sendo: "Pensar é dobrar, é duplicar o fora com um dentro que lhe é coextensivo" (DELEUZE, 2005, p. 126). 
Num texto intitulado $\bigcirc$ escritor como leitor (2017), Piglia nos apresenta, dentre outras coisas, alguns aspectos biográficos dos anos vividos pelo escritor Witold Gombrowicz na Argentina: a enorme pobreza material, a habitação num quarto de pensão compartilhado com mais três indivíduos, sobretudo a tentativa de fazer com que sua voz alcançasse o mundo, a partir de um país sul-americano, a partir de um idioma que não dominava totalmente, o castelhano - um "idioma da despossessão" (PIGLIA, 2017). Uma língua que aprendera no contato com as classes populares e marginalizadas, em bares, prostíbulos e locais do gênero, mas que fizera questão de assumir como seu idioma de criação. Como afirmação de certa potência concentrada na insuficiência e na inferioridade, ou no que assim, quem sabe, fosse considerado. Pobreza material e linguística assumida como condição de criação, como se a maior literatura ou as ideias mais surpreendentes só pudessem nascer de uma carência fundamental. Como se tal fundamento, constitutivo da própria existência, pudesse ser acessado apenas quando nos desfazemos de todo peso, das camadas e camadas de significação que nos impedem de dizer e pensar aquilo para o qual talvez ainda não existam palavras ou que esteja soterrado sob o seu excesso - ao mesmo tempo, sempre a partir delas. $O$ pensamento 4 e a literatura, nesse sentido, seriam produtos de uma espécie de linguagem negativa.

\section{Poesia como movimento de leitura e tradução}

Talvez pudéssemos - realizando um exercício, ao mesmo tempo, imaginativo e prático, que partisse das ideias acima esboçadas - tentar pensar na possibilidade de criação num ambiente de confinamento e distanciamento social. Tentar refletir sobre a aparente aporia que se expressa na necessidade de acesso a algo chamado Fora e, ao mesmo tempo, na condição de isolamento experimentada por grande parte da população. Sobre como poderíamos acessar o Fora sem deixarmos a nossa condição de dentro, de enclausurados, fundamental à manutenção de nossa saúde física e mental. É bem provável que se trate de uma questão de invenção e de produção com o que já se encontrava desde sempre ao nosso redor e nos acompanhava em nossa clausura. Porque, como sugere Deleuze, o Fora é coextensivo do dentro, dobra-se sobre ele, compondo seu interior. 
Este é possivelmente um dos ensinamentos que poderíamos absorver de Gombrowicz, o de que não necessitamos de uma extravagante riqueza de estímulos, de materiais ou de acontecimentos extraordinários para que a invenção aconteça. Obviamente ele se refere à literatura; suspeitamos, contudo, que tal princípio inventivo possa ser expandido para as práticas educativas e nos ajudar na produção de novos caminhos, mesmo em isolamento ou com restrições de contato social. A invenção desenvolve seu próprio substrato numa linguagem caracterizada pela despossessão (como aquela defendida por Gombrowicz), semelhantemente a uma criança que descobre as possibilidades do mundo à sua volta enquanto o experimenta.

Acreditamos que seja pertinente, neste ponto de nossa argumentação, o esclarecimento da prevalência do uso do termo "invenção" em detrimento da ideia de criação ou criatividade. Reverberamos a leitura de Deleuze, feita por Kastrup (2005), que enfatiza tal distinção. De maneira um tanto resumida, poderíamos dizer que, para a autora, enquanto a ideia de criatividade diria respeito à capacidade de resolução de problemas pré-estabelecidos, a invenção estaria relacionada à competência de criação dos próprios problemas. Afirmar a invenção nos coloca numa posição em que a operação dos elementos do mundo estaria sempre vinculada a certo estranhamento: pois tal posição é igualmente a negação "[...] da invariância das condições de possibilidade da cognição" (KASTRUP, 2005, p. 1274). Dessa forma, a invenção estaria vinculada à potência diferencial implicada no processo de conhecimento e na invenção do processo em si. Disso, decorre que os problemas e eventuais soluções, por ela produzidos, diferenciar-se-iam e se implicariam mutuamente numa invenção diferencial de si e do mundo como condição de produção de si e do mundo.

Voltando a Gombrowicz, importa lembrar sua conferência realizada em Buenos Aires, no dia 28 de agosto de 1947, intitulada "Contra os poetas" (PIGLIA, 20 17). Nela, assevera que não existe nenhum componente de um texto que o converta previamente em poético - algo como uma essência. $\bigcirc$ que tornaria um escrito poético seria a forma como o lemos. Pois quando classificamos um texto antecipadamente, antecipamos igualmente as expectativas do leitor, direcionamos seu olhar para que o leia da maneira assinalada. Nesse sentido, o modo como Gombrowicz concebe a literatura se aproxima muito do de Borges, pois este também afirmou que o que define um gênero literário não é algo que poderia ser qualificado como a sua essência, mas o modo 
como o lemos. A posição pode ser ilustrada pela seguinte sentença, proferida em sua famosa conferência sobre o romance policial: "Os gêneros literários dependem, talvez, menos dos textos que do modo como os textos são lidos" (BORGES, 2011 , p. 52).

Entretanto, se o poeta lque tem origem no termo grego poietes e significa aquele que faz) é alguém que produz algo com a linguagem, conforme nos ensina Pignatari (2005), podemos deduzir que o seu fazer não se diferenciaria, em essência, daqueles de outros artífices da linguagem, que a operação poética, ou de invenção, não estaria assentada em algo substancial. Por isso, Piglia (2017, p. 3) dirá que: "No centro da conferência está a noção de que a poesia também é uma operação que realizamos com os textos, uma disposição, e não uma essência." Operação que talvez possa ser transbordada para outras esferas da vida como a invenção de problemas (problemática), para, com ela, inventarmos uma aula, por exemplo. Não se trata das mesmas esferas, não são obviamente os mesmos inventos, porém possuem muito em comum. "Para o poeta, mergulhar na vida e mergulhar na linguagem é (quase) a mesma coisa" (PIGNATARI, 2005, p. 11 ).

A educação poderia, provavelmente, ser encarada como uma operação poética, como operação de invenção. Até porque, como nos lembra Pignatari (2005, p. 12): "Todos nós criamos, mas a (des)educação que recebemos nos orienta no sentido da descriação, no sentido de permanecermos apenas ao nível de competência." A criação e a invenção parecem ser procedimentos fundamentais da própria vida. E, se a poesia é um trabalho realizado sobre os textos, se colocarmos em prática o princípio de que "[...] a configuração da linguagem determina todos os sistemas semióticos [...]" (BENVENISTE apud TODOROV, 2003, p. 32), a educação, quem sabe, possa ser manufaturada de uma maneira análoga à poesia. Como operação poética sobre a realidade - olhar ou leitura inventiva sobre os elementos que compõem a existência -, intrincada dobradura "[...] na não emanação de um eu, mas a colocação em imanência de um sempre outro, de um não eu [...]. De modo que pensar será fazer com que o Outro, o Fora, o mais longínquo se torne minha intimidade" (PELBART, 1989, p. 136-137). Em uma realidade de circulação restrita, o Fora - de que falam Blanchot, Deleuze e Foucault, por onde circulam as forças diferenciais que possibilitam a invenção - deveria ser procurado em um dentro, nas coisas mínimas e mais corriqueiras. 
Contudo, o fato de sugerirmos afinidades entre as operações poética e educativa não pode ser confundido com a defesa de uma transposição automática de tais mecanismos de uma esfera a outra. Antes, gostaríamos de propor um processo de tradução que desmontasse as engrenagens da poesia para remontá-las, como uma máquina distinta, agora educativa, como operação de leitura e de escrita, sobretudo leitura atenta do mundo e dos textos (AQUINO; CORAZZA; ADÓ, 2018). Do mundo e de seus textos: do mundo feito um infinito texto. Pois a operação tradutória não diz respeito apenas à transposição dos conteúdos de determinado escrito de um idioma a outro. "Não se traduz o que é linguagem num texto, mas o que é não linguagem" (CAMPOS, 2013 , p. 3). Ou, em nosso caso, não apenas linguagem, mas determinada ética envolvida no fazer poético e sua tradução como abertura das palavras e do mundo em formas renovadas de existência (CORAZZA, 2016). Cabe ao leitor-professor, leitor-tradutor ou professor-poeta a invenção de si mesmo, de seu mundo e consequentemente do tipo de educação a que vincula sua prática diária. "Esse exercício tradutório da docência consiste em um modo de colocar à mostra e, mais além, de enfatizar o próprio processo de construção e de criação do nosso mundo comum" (AQUINO; CORAZZA; ADÓ, 2018, p. 10). Invenção-intervenção através dos elementos comuns e cotidianos.

Teríamos, então, que buscar um modo de expressão através de tais elementos insignificantes para com eles compormos algo que provavelmente não diria respeito apenas a nossas vidas privadas. Através de um olhar ou de uma leitura direcionada aos pequenos elementos à nossa volta, olhares ou leituras menores para uma poética menor de uma educação menor - o que não quer dizer menos importante, mas menor no sentido proposto por Deleuze e Guattari (2017) em suas leituras de Kafka.

\section{A invenção de uma saúde através da leitura}

O Fora - mais do que nunca, nestes tempos de exceção e isolamento - teria de ser alcançado em sua porção que se dobra sobre o dentro que habitamos para que conseguíssemos acessar as forças intensivas através das quais poderíamos compor uma educação que expandisse nossas energias em vez de drená-las ainda mais. A invenção poética em educação seria, por conseguinte, caracterizada por uma maneira de ler (ou de um olhar) que se dobra 
sobre si mesma em busca das forças diferenciais e intensivas, necessárias à constituição de novas formas. Devemos, aqui, contudo, entender que se certa prática poética, vinculada por nós ao fazer em educação, aproxima-se em alguns pontos daquela dos poetas, ela se distancia em outros tantos. Porém, assim como Gombrowicz apontava para o fato de não haver em literatura uma essência ou elementos internos aos textos que os caracterizem como poéticos, tampouco o há em educação. Ainda assim, seria equivocado entendermos a educação como uma ramificação do fazer artístico (AQUINO; CORAZZA; ADÓ, 2018). É bem provável que a invenção poética em educação se caracterize pela necessidade de uma tomada de consciência (por parte do leitor-professor, do leitor-tradutor ou do professor-poeta) do inessencialismo do mundo - pela constatação de que "[...] não há dia claro para aqueles docentes que se embrenham na tragicidade poética dos acontecimentos, visto que esta possui mais teor subtrativo do que cumulativo[...]" (AQUINO; CORAZZA; ADÓ, 20 18, p. 3). Porquanto, devemos inventar as questões mesmas de que partiremos.

Suspeitamos de que a invenção (seja ela literária ou educacional) esteja sempre relacionada a determinado uso dos elementos com os quais se trabalha. Um uso radical que os modela até a fronteira da desfiguração, até o 8 limite do quase rompimento de sua própria composição, em que se tornariam irreconhecíveis. Seguindo Deleuze (2011), poderíamos chamar isso de "estado de devir". Limite por onde circulam e se contorcem as "coisas-acontecimentos" ainda não formadas. Quando conseguimos tocar, ainda que rapidamente, tal fronteira, por alguns instantes, vislumbramos, somos atravessados e atravessamos as forças informes do Fora por onde passa toda possibilidade de invenção.

Não menos importante, no tocante à nossa argumentação, é o fato de que Deleuze (201 1) descreverá a literatura como um tipo específico de prática de saúde, tendo como principal propriedade o que chamou de "função fabuladora". O autor identifica no escritor uma espécie de "médico de si próprio e do mundo". Então, a literatura - operada através de sua função fabuladora - apresentar-se-ia como um empreendimento de saúde, consistiria em inventar uma vida (um povo) por vir ou potencial ainda inexistente. Uma existência em estado de devir, por isso, sempre minoritária, devindo em infinitos caminhos e possibilidades.

Da apresentação de alguns aspectos da vida e da obra de Gombrowicz, feita por Piglia, poderíamos incorporar dois princípios 
operacionais básicos à tentativa de invenção de uma educação poética, mesmo que estejamos numa situação de enclausuramento - ou por causa dela. Como movimento de partida (que inicia o sempre já iniciado), a leitura converte-se em combustível e engrenagem produtiva; como matéria expressiva (produto-produtivo), engendram-se elementos, aos quais não dominamos completamente: de uma linguagem ou "idioma da despossessão" (PIGLIA, 2017, p. 2). Como se fizéssemos parte, de alguma forma, de certa estirpe gombrowicziana: daqueles criadores que, com o mínimo de recursos, inventam um mundo sem fim, prodigamente povoado. Eles deslocam as suas invenções até o limite, porque sempre já partem de uma zona onde a escassez deixa de ser o extremo oposto da abundância para se converter na própria abundância, sua subversão e condição. A abundância que se dobra sobre a escassez movimento em que os dois polos podem deixar de ser conflitantes e passar a ser complementares - como um Fora que se dobra sobre um dentro e vice-versa. Mas, para que tal operação ocorra, são necessárias condições muito específicas.

\section{Máquina de leitura}

Em seu romance intitulado A cidade ausente, Piglia (1993) nos apresenta uma máquina produtora de relatos. Um equipamento inicialmente projetado para produzir traduções de forma automatizada, mas que, por um defeito em seu funcionamento, passa a fabricar histórias cuja verificação da veracidade é praticamente impossível. O governo argentino pretende desativáto, pois estaria interferindo em seu controle das narrativas sociais, introduzindo no imaginário coletivo narrativas que o Estado já não consegue dizer se são verdadeiras ou falsas. Identificamos uma curiosa semelhança entre tal máquina, engendrada pela imaginação pigliana, e a máquina ficcional pensada por Deleuze e Guattari (2017), que poderíamos chamar, aqui, de máquina literária e consequentemente (ou mais ainda) leitora. A característica principal do funcionamento de ambas poderia ser iluminada pelo seguinte diálogo, protagonizado pela personagem Elena (ela mesma uma máquina e consciência onipresente e coletiva que embaralha os relatos fictícios e reais), no romance A cidade ausente: "- $O$ que é ser uma máquina? - perguntou o doutor Arana. - Nada - disse ela. - Uma máquina não é; uma máquina funciona." (PIGLIA, 1993, p. 56). O que interliga tais concepções é o que Lapoujade (2015, p. 
129) chamou de "maquinismo" deleuziano ao se referir à sua lógica de composição. Nas palavras do próprio filósofo: "Máquina dionisíaca de produzir o sentido [...]" (DELEUZE, 1979, p. 1 10). Ou os sentidos, sempre no plural. Maquinismo que operacionaliza o próprio fluxo da vida. Porque, para Deleuze (igualmente em seus textos escritos em parceria com Guattari), se existe algo que poderíamos chamar de uma natureza humana ela se confundiria com a produção dos seres humanos por eles mesmos, bem como com a produção de seus objetos. Os humanos se relacionariam com o mundo o fabricando através deste maquinismo generalizado, da produção de diferentes máquinas e da produção realizada por tais máquinas como corte no fluxo energético-caótico da vida. "É assim que todos somos 'bricoleurs'; cada um com suas pequenas máquinas. Uma máquina-órgão para uma máquina-energia, sempre fluxos e cortes. [...] Algo se produz: efeitos de máquinas e não metáforas" (DELEUZE, GUATTARI, 2017 , p. 111. Máquinas de diferentes naturezas, ligadas umas às outras, produtoras de novos fluxos e novas máquinas - maquinismo ilimitado.

No caso de Gombrowicz e de sua invenção, a produção de sua máquina literária, ele elege como ponto de partida, como lógica de funcionamento, ou de "corte no caos" (DELEUZE, 2004), o modo como os diferentes

10 textos podem ser lidos. Se existe algo que poderíamos chamar (um tanto indefinidamente) de maquinismo gombrowicziano ele se caracterizaria fundamentalmente pela maneira como lemos os diferentes textos, concepção muito semelhante àquela professada por Borges.

Monegal (1 980), ao analisar o processo de escrita de Borges, faz alusão a um artigo de Genette que aponta uma característica que vai ao encontro da ideia de uma máquina literária nos moldes definidos por Deleuze e, em alguma medida, por Guattari. Os textos de Borges seriam uma espécie de apanhado dos diversos matizes (dos desdobramentos) de uma determinada ideia, tema ou metáfora ao longo do tempo. Genette dirá que a escrita de Borges "[...] parece possuída por um estranho demônio da associação" (GENETTE apud MONEGAL, 1980, p. 26). Semelhantemente a Gombrowicz, a raiz do maquinismo de Borges encontra-se em seu modo idiossincrático de leitura. "É nessa perspectiva labiríntica e vertiginosa que Borges faz de seu universo leitor uma relação disposta à escritura." (ADÓ, 2016, p. 136). Como nos mostra Adó (2016, p. 136) - num texto em que comenta a relação entre leitura e escrita em Borges -, importa, em seu método, o cruzamento labiríntico entre as leituras (de textos ou de livros) que não respeita as fronteiras pré-estabelecidas entre os 
gêneros: "Como se as frases de um texto fossem concatenadas por um bibliotecário que, a cada ordenar e reordenar de uma biblioteca, vai inventariando frases, palavras, parágrafos de livros dispersos [...]" - inventariando e inventado, a partir delas (e com elas), séries inéditas e novas máquinas-fluxos.

Esse é um modo de ler curiosamente muito semelhante ao de Deleuze e Guattari: "De resto líamos muito, não livros inteiros, mas pedaços" (DELEUZE, 2013 , p. 24). Todo escritor (ou fabricante de tais máquinas) talvez seja um traidor, um mentiroso contumaz e um prestidigitador - "[...] que trai o que lê, que se desvia e ficcionaliza" (PIGLIA, 200 1, p. 7, tradução nossa), pois procura algo que não está dito no texto, procura extrair certa energia que o corta e que está presente igualmente em todas as coisas do mundo. "O que buscamos num livro é a maneira pela qual ele faz passar alguma coisa que escapa aos códigos: [...] linhas de descodificação absoluta [...]" (DELEUZE, 2013, p. 36). Porquanto a ficção trabalha num sentido de construir narrativas que habitam uma zona de indecidibilidade, circulam por um espaço onde os discursos não poderiam mais ser considerados nem verdadeiros nem falsos (PIGLIA, 2001), dado que o que está em jogo é a produção da potência ficcional, pura potência. Ou se, por algum motivo, tivéssemos de escolher entre um dos polos, ficaríamos sempre ao lado do falso, porque, segundo Deleuze, o falso é a própria potência do tempo, que o coloca em devir, "[...] põe em questão todo o modelo formal de verdade" (DELEUZE, 2013 , p. 89), potência do imaginário (do cristal) que ocupa tal zona de indecidibilidade entre o real e o irreal.

Como base, como possibilidade de invenção em educação, defendemos um tipo de leitura que falseia os materiais com que se depara e os desrespeita. Mas que, justamente por isso, eleva a deferência a outro nível, pois habita de tal forma, de maneira tão amorosa aquilo que lê (sejam textos, livros, ou a própria vida), que o converte em seu, mesmo que tal uso se distancie daquele proposto originalmente pelo autor ou pelas convenções sociais. Adultera para extrair a potência do falso, para colocar o tempo em devir e questionar os usos estabelecidos para produzir potências da vida mesma, ainda que sob as condições mais adversas. Espécie de amor fati nietzscheano, que extrai potência de todas as coisas, como elas se apresentam, e faz delas o combustível de criação da existência, inventa sua vida própria: "Que minha única negação seja desviar o olhar! $\mathrm{E}$, tudo somado e em suma: quero ser, algum dia, apenas alguém que diz Sim!" (NIETZSCHE, 201 1, p. 164). Seguindo os passos de Gombrowicz e igualmente de Borges, deveríamos 
fazer do modo de ler o substrato de nossa escrita, um processo em que "[...] seria ela mesma continente e conteúdo de um multiverso travado pelo leitor [...]" (ADÓ, 2016, p. 137-138) - leitura como invenção da escrita, da educação e da vida. Dizer sim.

\section{Linguagem da despossessão e da vida}

Se estamos tentando pensar os possíveis caminhos por onde movimentaríamos a invenção de uma educação como processo análogo ao fazer poético e se a invenção, como a entendemos a partir de Kastrup, difere da criação (ou da criatividade) pelo fato da primeira não se resumir à mera resolução de problemas preestabelecidos, mas por inventar os próprios problemas, diríamos, então, que nenhum passo poderia ser presumido como algo não problemático. Por isso, defendemos que a invenção de uma educação, principalmente diante das condições inéditas (e de exceção) em que nos encontramos, deve inventar, além de novos problemas, a linguagem mesma com que tratará os problemas concebidos. Mais uma vez, acompanhamos as formulações de Gombrowicz, desta vez, de uma anotação em seu diário,

12 onde diz que provavelmente "[...] o escândalo seja ainda não termos uma língua para expressar nossa ignorância" (GOMBROWICZ apud PIGLIA, 2017, p. 2). Teríamos, então, que inventar uma nova linguagem como a de uma criança que explora o mundo e que expresse nossa ausência de conhecimento diante das circunstâncias inéditas de ensino e de vida que se apresentam a todos. Como um tipo de língua minoritária - análoga àquela pensada por Deleuze e Guattari - que trabalha com materiais expressivos ínfimos.

Uma língua menor caracteriza-se, na verdade, pela utilização inventada por uma minoria de uma língua maior ou dominante. A desterritorialização de tal língua, sempre com uso político e como máquina de guerra, visando a "[...] forjar os meios de uma outra consciência e de uma outra sensibilidade [...]" (DELEUZE; GUATTARRI, 2017, p. 37). Assim, a literatura menor se aproximaria bastante da concepção de Gombrowicz sobre a literatura e sua produção vinculada à língua dos despossuídos e dos marginalizados com a qual se relacionou em seu exílio na Argentina, dado que "[...] trabalha sobre a afasia como condição de estilo [...]" (PIGLIA, 2017, p. 2). Tendo em vista o uso que propomos, teríamos, por conseguinte, que empregar a língua de uma forma 
intensiva, até uma imprecisa fronteira que a converte em materialidade que alimenta a criação - num ponto onde a própria língua encontra-se em iminente despedaçamento, em seu limite, "[...] para liberar uma matéria viva expressiva que fala por ela mesma e não tem mais necessidade de ser formada [...]" (DELEUZE; GUATTARRI, 2017, p. 43).

Obviamente Witold Gombrowicz não conheceu Gilles Deleuze, mas Gilles Deleuze conheceu a obra de Witold Gombrowicz. $\bigcirc$ que pode ser verificado em diversas passagens do filósofo francês. Como em Diferença e repetição, em que Deleuze utiliza Gombrowicz a título de exemplo de um tipo de escritor que fora capaz de transformar o cosmo em livro e vice-versa: "caos = cosmo" (DELEUZE, 20 18). Ou em outra passagem de Crítica e clínica em que Deleuze emprega o escritor justamente como exemplo de literatura ligada a algo da ordem do informe e do inacabamento: "Escrever é um caso de devir, sempre inacabado, como sempre em via de fazer-se, e que extravasa qualquer matéria vivível ou vivida" (DELEUZE, 201 1, p. 11). É o caso da obra-vida - verdadeira "vidarbo" (CORAZZA, 2013, p. 11 1): vida que se confunde com a escrita, com a obra - de Gombrowicz, parece-nos (também pareceu ao filósofo). Porquanto, para Deleuze, escrever, fazer com que a escrita entre num estado de devir, é fazer com que o produzido habite uma zona de vizinhança às coisas, onde elas e o texto seriam indistinguíveis e adquiririam formas imprevistas que anteriormente não existiam: "O devir está sempre 'entre' ou no "meio'" (DELEUZE, 201 1, p. 12). E a forma com que a língua alcança o estado de devir materializa-se através dos desvios que inventa, sobretudo sintáticos, mesmo com todos os riscos implicados. "A sintaxe é o conjunto de desvios necessários criados a cada vez para revelar a vida nas coisas." (DELEUZE, 2011 , p. 12). Porém lembremos, com o filósofo, que revelar a vida nas coisas implica compreender seu caráter imanente, inclusive quando falamos do pensamento como vida, obra e produção. $\bigcirc$ pensamento que é produzido no Fora, a partir dele, é sempre imanente e, neste sentido, confunde-se com a vida mesma: "Uma vida é a imanência da imanência, a imanência absoluta: ela é potência completa, beatitude completa" (DELEUZE, 2012, p. 12).

Entretanto, voltemos aos desvios sintáticos necessários implicados numa literatura em estado de devir. Tais desvios aproximam-se de uma gagueira (de um defeito da voz) que, em alguns momentos muito específicos, pode chegar a confundir-se com a fala (que, contudo, a excede), quando expressa um tipo especial de fala: a "[...] fala poética, que efetua toda a potência de 
bifurcação e de variação, de heterogênese e de modulação da própria língua" (DELEUZE, 2011 , p. 140). Daí a potência contida numa educação que se aproxime de um fazer poético: a possibilidade de revelar a vida contida na educação em si. Deleuze escreveu um belíssimo texto intitulado: A imanência: uma vida... (201 1), talvez também pudéssemos - ao falar do procedimento poético que revela a vida na educação, vida que é a própria imanência parafrasear o filósofo e nos referirmos à educação da seguinte maneira: a educação: uma vida...

\section{O dentro como um Fora}

pensamento operaria, como vimos, através da dobradura do Fora e em sua indiferenciação com um dentro que the seria coextensivo. Inferimos, disso tudo, que, quem sabe, fosse justo pensarmos que o Fora, caracterizado por fluxos componentes do pensamento, pudesse ser buscado num dentro, num mínimo de elementos (em sua depuração) que movimentassem o pensar com uma força turbilhonar análoga à infinidade dos fluxos do Fora. Um mínimo,

14 correlato ao castelhano de Gombrowicz, como espécie de idioma da despossessão proposto por Piglia. Ou, como no comentário de Adó (2013) sobre Valéry em seu Introdução ao método de Leonardo da Vinci (1979), em que sugere que, para o autor, nossa escassez poderia ser convertida em fecundidade, porque tal carência nos obrigaria a "inventar a falta" (ADÓ, 2013). A operação engendraria uma vivacidade de tipo superior, muito mais potente. Identificamos aqui uma ligação entre o que Adó (2013) chamou de uma "autocomédia do intelecto" e o Fora que se dobra sobre o dentro: o dentro (mínimo ou despossessão) como Fora virado pelo avesso. Autocomédia do intelecto menos interessada na produção ou descoberta de uma verdade do que na produção de sua própria potência, que se realiza na "contingência de composição" (ADÓ, 2013) de suas narrativas e experimentações ou autoexperimentações: autoprodução do pensamento e autoficcionalização.

Quando elegemos como material de trabalho a ficção em vez da verdade, não estamos negando, contudo, seu estatuto ou relevância, ainda que frágeis. Ao invés disso, problematizamos ao afirmamos "[...] que a verdade é segunda, que não está dada mas deve ser criada, que não é princípio mas produto: produto de um trabalho ficcional, subjacente a todo o pensamento 
preocupado em agenciar o múltiplo [...]" (PELLEJERO, 2012, p. 282). Como argumenta Piglia: "A realidade é tecida por ficções" (200 1, p. 7, tradução nossa). Entretanto, muito mais do que produzir a verdade, a ficção a tem como substrato, porém não como objetivo último, pois se movimenta num campo discursivo que não poderia ser considerado nem verdadeiro nem falso (PIGLIA, 2001 1). Piglia, ainda dirá que a ficção visa sempre ao futuro ou ao que ainda não é, nesse sentido, fazendo coro com Deleuze, pois este, como vimos, afirma que a literatura (ou a ficção) inventa um povo (uma vida) que ainda não existe ou está por vir: "Constrói o novo com os restos do existente" (PIGLIA, 200 l, p. 9, tradução nossa).

\section{Ficção mínima}

A saída do isolamento - sem sairmos fisicamente - talvez residisse desde o início nele mesmo, na transmutação de determinada pobreza em potência, em sua própria transformação. Na invenção de uma sintaxe muito particular, vinculada à exiguidade, que possuiria o atributo de converter o cotidiano em devir, através da produção ficcional, metamorfoseando-o numa autofabulação como autocomédia do intelecto. E que, principalmente por estarmos falando de educação, trabalharia com textos, mas também encararia a realidade como um grande texto a ser produzido. Isso porque o mundo dos humanos, muito provavelmente, é inseparável da linguagem - de uma espécie de leitura (e escrita) do mundo que enreda o próprio mundo e o produz. Mundanidade de homens e mulheres (ou realidade se preferirem) imersos no que Derrida chamou de "jogo" (DERRIDA, 2017, p. 8), em que já não existiria nenhuma exterioridade à linguagem a ser buscada. Mundo constituído de significantes de significantes, em que o significado já é, desde sempre, ele mesmo, um significante. Operar no mundo e na realidade seria operar o mundo e a realidade, produzi-los sempre como significantes, através da escrita que, como defendemos, é inseparável de determinado modo de leitura (de uma ética leitora). Nesse caso, o modo como produzimos a realidade está condicionado ao modo como a lemos e Deleuze parece concordar com tal princípio: "[...] nós lemos o mundo mais do que o vemos" (DELEUZE, 2013, p. 201).

Após esse breve percurso, acima delineado, talvez pudéssemos voltar ao nosso problema inicial e, agora melhor aparelhados, tentar responder à 
pergunta (ou inventar outras tantas) sobre como seria possível que algo novo, o pensamento, principalmente, fosse produzido em condições de isolamento e, em muitos casos, na escassez de recursos ou estímulos. Olhando mais de perto, podemos perceber que a pobreza talvez seja quase sempre aparente e que aquilo que tomamos como pobreza seja, na verdade, certa invariância sintática do mundo, ou sua monotonia.

Teríamos, por conseguinte, de ativar a operação de nosso idioma da despossessão (o que se confunde com inventá-lo), não para nos apossarmos do mundo ou tomarmos o controle, mas para falar daquilo que não sabemos, ou seja, desapossarmo-nos do que nunca tivemos posse. A possibilidade de alguma educação poética passa pela invenção de outra sintaxe para as coisas do mundo, mesmo que este se reduza ao interior de nossa casa ou à tela de um computador ou smartphone.

O ordenamento da realidade não diz respeito a algum tipo de essência ou propriedade intrínseca, muito menos a uma verdade pré-estabelecida. Temos, então, que ler o mundo como uma criança que aprende a decifrá-lo, inventar nossa sintaxe particular como possibilidade de abertura de devires e de imprevisibilidade. Temos que traduzir os princípios de funcionamento da 16 máquina literária para uma máquina educativa que se conecta às outras tantas que povoam o mundo, mesmo que, em tal operação, corramos o risco de nos perder: e este risco é inerente. Tudo parte de uma disposição (ou desejo) para lermos o mundo como um grande poema, o que implicaria igualmente numa torção na familiaridade com que nele nos movimentamos. Porquanto, a linguagem poética (o que demanda uma leitura particular) não trabalha visando à coesão, pelo contrário, ela produz dispersão (PELBART, 2007). Por isso, está ligada fortemente ao pensar, pois, para Deleuze, pensar se relaciona sempre com o Fora, com a movimentação infinita de suas forças que devem ser tocadas para que algo novo possa surgir como no caso do pensamento, por exemplo.

A produção de uma pequena máquina-literária, que é igualmente poético-educativa, diz respeito muito mais a certa postura diante da realidade, ou a certo modo de leitura. Numa situação de confinamento, refere-se ao trabalho realizado, numa dimensão pouco precisa, no ponto de articulação em que o Fora se dobra sobre o dentro e quem sabe o dentro possa igualmente dobrar-se em direção ao Fora como as duas faces de um mesmo fluxo de forças - macrocosmo e microcosmo. Nossa leitura terá que produzir a variação: 
um desvio sintático radical que ameaça desfigurar o que lê até o limite da afasia. Gombrowicz encontrou no castelhano um veículo para sua expressão. Teríamos, cada um de nós, que descobrir ou inventar nossos idiomas minoritários e com eles colocar a língua, a educação e o mundo para vibrar.

\section{Nota}

1 presente trabalho foi realizado com apoio da Coordenação de Aperfeiçoamento de Pessoal de Nível Superior (CAPES) - Código de Financiamento 001 / "This study was financed in part by the Coordenação de Aperfeiçoamento de Pessoal de Nível Superior - Brasil (CAPES) - Finance Code 001 .

\section{Referências}

ADÓ, Máximo Daniel Lamela. Educação potencial: autocomédia do intelecto. $2013.195 f$. (Tese de Doutorado) - Programa de Pós-Graduação em Educação, Universidade Federal do Rio Grande do Sul, 2013.

ADÓ, Máximo Daniel Lamela. Aporias literárias: questões borgeanas na educação. Revista Digital do LAV, Santa Maria, v. 9, n. 2, p. 133-145, mai./ago. 2016. Disponível em: http://dx.doi.org/10.5902/1983734823517. Acesso em: 20 fev. 2019.

AQUINO, Julio Groppa; CORAZZA, Sandra Mara; ADÓ, Máximo Daniel Lamela. Por alguma poética na educação: a didática como criação. Educação em Revista, Belo Horizonte, v. 34, jan. 2018. Disponível em: https://www.scielo.br/scielo.php?script=sci_arttext\&pi $d=S 0102-46982018000100108$. Acesso em: 3 ago. 2019.

BLANCHOT, Maurice. O espaço literário. Tradução Álvaro Cabral. Rio de Janeiro: Editora Rocco, 2011.

BORGES, Jorge Luis. Borges oral \& sete noites. Tradução Heloisa Jahn. São Paulo: Companhia das Letras, 2011.

CAMPOS, Haroldo de. Da tradução como criação e como crítica. In: TÁPIA, Marcelo; NÓBREGA, Thelma Médici (org.). Transcriação. São Paulo: Perspectiva, 2013.

CORAZZA, Sandra Mara. O que se transcria em educação? Porto Alegre: Editora Doisa, 2013.

CORAZZA, Sandra Mara. Currículo e didática da tradução: vontade, criação e crítica. Educação \& Realidade, Porto Alegre, v. 41, n. 4, p. 1313-1335, out./dez. 2016. Disponível em: https://www.scielo.br/scielo.php?pid=S217562362016005004102\&s cript=sci_abstract\&tlng=pt. Acesso em: 6 out. 2019. 
DELEUZE, Gilles. Logica do sentido. Tradução Luiz Roberto Salinas Fortes. São Paulo: Perspectiva/Editora da Universidade de São Paulo, 1974.

DELEUZE, Gilles. Imanência: uma vida... Tradução Tomaz Tadeu. Educação \& Realidade, v. 27, n. 2, p. 10-18, jul./dez. 2002. Disponível em: https://seer.ufrgs.br/educacaoerealidade/article/view/31079. Acesso em: 23 set. 2019.

DELEUZE, Gilles. O que é a filosofia? Tradução Bento Prado Júnior. Rio de Janeiro: Editora $34,2004$.

DELEUZE, Gilles. Foucault. Tradução Claudia Sant'Anna Martins. São Paulo: Editora Brasiliense, 2005.

DELEUZE, Gilles. Crítica e clínica. Tradução Peter Pál Pelbart. São Paulo: Editora 34, 2011.

DELEUZE, Gilles. Conversações. Tradução Peter Pál Pelbart. São Paulo: Editora 34, 2013.

DELEUZE, Gilles. Diferença e repetição. Tradução Luiz Orlandi e Roberto Machado. Rio de Janeiro; São Paulo: Editora Paz e Terra, 2018.

DELEUZE, Gilles; GUATTARI, Félix. O anti-Édipo: capitalismo e esquizofrenia. Tradução Luiz Orlandi. São Paulo: Editora 34, 2010.

DELEUZE, Gilles; GUATTARI, Félix. Kafka: por uma literatura menor. Tradução Cláudia Vieira 18 da Silva. Belo Horizonte: Editora Autêntica, 2017.

DERRIDA, Jacques. Gramatologia. Tradução Miriam Chnaiderman e Renato Janine Ribeiro. São Paulo: Editora Perspectiva, 2017.

FOUCAULT, Michel. O pensamento do exterior. In: MOTTA, Manuel Barros da (org.). Estética: literatura e pintura, música e cinema. Tradução Inês Autran Dourado Barbosa. Rio de Janeiro: Editora Forense Universitária, 2006.

KASTRUP, Virginia. Políticas cognitivas na formação do professor e o problema do devir-mestre. Educação \& Sociedade, Campinas, v. 26, n. 93, p. 1273-1288, set./dez. 2005. Disponível em: https://doi.org/10.1590/s0101-73302005000400010. Acesso em: 15 ago. 2020.

LAPOUJADE, David. Deleuze, os movimentos aberrantes. Tradução Laymert Garcia dos Santos. São Paulo: Editora n-1, 2015.

LEVY, Tatiana Salem. A experiência do fora: Blanchot, Foucault e Deleuze. Rio de Janeiro: Editora Civilização Brasileira, 2011.

MONEGAL, Emir Rodríguez. Borges: uma poética da leitura. Tradução Irlemar Chiampi. São Paulo: Editora Perspectiva, 1980. 
NIETZSCHE, Friedrich. A gaia ciência. Tradução Antonio Carlos Braga. São Paulo: Editora Escala, 2011 .

PELBART, Peter Pál. Da clausura do fora ao fora da clausura: loucura e desrazão. São Paulo: Editora Brasiliense, 1989.

PELBART, Peter Pál. Literatura e loucura: da exterioridade à imanência. In: LINS, Daniel. (org.). Nietzsche/Deleuze: imagem, literatura e educação: Simpósio Internacional de Filosofia. Rio de Janeiro: Forense Universitária; Fortaleza: Fundação de Cultura, Esporte e Turismo, 2007.

PELLEJERO, Eduardo. A realidade da ficção: uma aproximação a partir da filosofia francesa contemporânea. In: KANGUSSU, Imaculada; SILVA, Cintia Vieira (org.). Congresso internacional fantasia \& crítica, Belo Horizonte: ABRE, 2012.

PIGLIA, Ricardo. A cidade ausente. Tradução Sérgio Molina. São Paulo: Editora lluminuras, 1993.

PIGLIA, Ricardo. Crítica y ficción. Barcelona: Anagrama, 2001.

PIGLIA, Ricardo. O escritor como leitor. Serrote, n. 32, jan. 2017. Disponível em: https:// www.revistaserrote.com.br/2017/01/o-escritor-como-leitor-por-ricardo-piglia/. Acesso em: 30 fev. 2019.

PIGNATARI, Décio. O que é comunicação poética. São Paulo: Ateliê Editorial, 2005.

TODOROV, Tzvetan. Poética da prosa. Tradução Claudia Berliner. São Paulo: Editora Martins Fontes, 2003

VALÉRY, Paul. Introdução ao método de Leonardo da Vinci. Tradução José Martins Garcia. Lisboa: Editora Arcádia, 1979.

Mestrando Luiz Carlos Quirino da Silva Universidade Federal do Rio Grande do Sul (Brasil) Programa de Pós-graduação em Educação Grupo de Pesquisa: POÏEIN - Microscopias. Educação. Imanência Orcid id: https:/ / orcid.org/0000-0003-4715-8932 E-mail: luizcabelo $1 @$ hotmail.com 
Artigo

Inventar o fora como um dentro e fazer da clausura uma educação

Prof. Dr. Máximo Daniel Lamela Adó

Universidade Federal do Rio Grande do Sul (Brasil)

Faculdade de Educação

Professor permanente no Programa de Pós-graduação em Educação Grupo de Pesquisa: POÏEIN - Microscopias. Educação. Imanência Orcid id: https:/ / orcid.org/0000-0002-7643-1785

E-mail: maximo.lamela@gmail.com

Recebido 22 set. 2021

Aceito 17 nov. 2021 